\title{
The adoption of bitcoins technology: The difference between perceived future expectation and intention to use bitcoins: Does social influence matter?
}

\author{
Ibrahim Almarashdeh ${ }^{1}$, Kamal Eldin Eldaw ${ }^{2}$, Mutasem Alsmadi ${ }^{3}$, Fahad Alghamdi ${ }^{4}$, \\ Ghaith Jaradat $^{5}$, Ahmad Althunibat ${ }^{6}$, Malek Alzaqebah ${ }^{7}$, Rami Mustafa A. Mohammad $^{8}$ \\ ${ }_{1,2,3,4}$ College of Applied Studies and Community Service, Imam Abdurrahman Bin Faisal University, Al-Dammam, \\ Saudi Arabia \\ ${ }^{5}$ Department of Computer Science, Faculty of Computer Science and Information Technology, Jerash University, Jordan \\ ${ }^{6}$ Software Engineering Department, Faculty of Science and IT, Al-Zaytoonah University of Jordan, Amman, Jordan \\ ${ }^{7}$ Department of Mathematics, College of Science, Imam Abdulrahman Bin Faisal University, Dammam, Saudi Arabia \\ ${ }^{8}$ Computer Information Systems Department, College of Computer Science and Information Technology, Imam
} Abdulrahman Bin Faisal University, Dammam, Saudi Arabia

\begin{tabular}{l} 
Article Info \\
\hline Article history: \\
Received Feb 7, 2020 \\
Revised May 21, 2021 \\
Accepted Jun 10, 2021 \\
\hline
\end{tabular}

\section{Keywords:}

Adoption risk

Bitcoins

Performance expectancy

Social influence

Technology acceptance

\begin{abstract}
Bitcoin is a decentralized system that tries to become a solution to the shortcomings of fiat and gold-based currencies. Considering its newness, the adoption level of bitcoin is yet understood. Hence, several variables are proposed in this work in examining user perceptions regarding performance expectancy, effort expectancy, trust, adoption risk, decentralization and social influence interplay, with the context of user's future expectation and behavioral intentions to use bitcoins. Data were gathered from 293 completed questionnaire and analised using AMOS 18. The outcomes prove the sound predictability of the proposed model regarding user's future expectations and intentions toward bitcoins. All hypotheses were supported, they were significantly affecting the dependent variables. Social influence was found as the highest predictor of behavioral intention to negatively utilize bitcoins. The significant impact of social influence, adoption risk and effort expectancy which affect behavioral intention to use bitcoins the most, are demonstrated in this study. Bitcoins should thus, present an effective, feasible and personalized program which will assist efficient usage among users. Additionally, the impacts of social influence, adoption risk and perceived trust on behavioral intention to utilize new technology were compared, and their direct path was tested together, for the first time in this context.
\end{abstract}

This is an open access article under the CC BY-SA license.

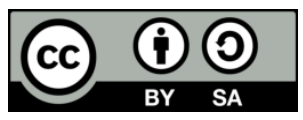

\section{Corresponding Author:}

Ibrahim Almarashdeh

Department of Management Information Systems

College of Applied Studies and Community Service

Imam Abdulrahman Bin Faisal University, Saudi Arabia

Email: ibramars@gmail.com

\section{INTRODUCTION}

The technology revolution brings a lot of innovation to our lives. In the meanwhile, the world encountered the biggest global financial crisis. The crisis directed people and institutions to query about the state-issued currencies management, particularly, the government and financial sector [1]. The present-day market furnishes users with countless of state-of-the-art systems for money payment. For these systems, 
many of them are created on platforms such as the internet, digital storage card, and mobile phone. There has been increasing growth to these unconventional systems of payment and among them include Google Wallet, Apple Pay, PayPal, BitPesa and so forth [2]. Nakamoto was the founder of a digital currency called bitcoin and this system offers a low-cost, secure platform usable for electronic payments. By 2009 bitcoin network started to rapidly develop. As reported in [3], the dramatic expansion of bitcoin network in addition to the distinguishing features of currency have grabbed the attention of governments.

Beyond payment systems which rely on fiat money (currency), the digital currency, which is increasing in usage, has greater flexibility, innovativeness, and speed in making payment for services and goods. There are many different digital currencies but the most popularly used today is bitcoin. As a cryptocurrency, bitcoin is the best of its kind, and it employs the Internet power to process transactions [2].

Advancements in payment systems can potentially transform the economy in many ways: transfer of cross-border remittances, generation of economically sustainable micropayments, secure online transaction, and distinctive enforcement of contracts [1]-[4]. It has therefore been acknowledged that now is the appropriate time to have a safe and practical money system for global economic interactions, with no linkage to leading financial institutions or governments. Furthermore, the presently used international transfer systems are not only costly, but also lack flexibility, and this imposes excessive costs on both individuals and organizations. Besides that, there are also those who opined that money system should not be under the watch of government, and that such system should be made available as well. Accordingly, previous researchers reported numerous socioeconomic forces driving the demand for unconventional currencies, and these forces include technology, environmentalism, localism, technology, political economy, inefficiencies, financial freedom, and speculation [4].

Historically, the competitive forces that led to the superiority of certain exchange media over others in the fulfilment of needs can be scrutinized. Accordingly, the success of digital currencies is dictated by their capacity in satisfying needs in the manner that they should, or in a manner that is superior to the competitors or the conventional fiat [4]. In this regard, should the use digital currencies become more expansive as opposed to those of conventional, it may be worthy to discuss if the traditional money can still be in existence in the long run among the digital currencies.

The intent of user to use bitcoins remains open for scrutiny. Furthermore, as reported in the literature [5], empirical studies on the perceptions of bitcoin users have been too few. In this regard, the biggest and still unanswered question is definitely on whether the whole world will want to have full digital currency in future or not? [4]. Also, it is important to be aware of what people anticipate from bitcoins in future. As such, the main purpose of this study is to examine the intent of people in the adoption of bitcoin. This study will specifically examine the factors which might impact bitcoin adoption. Ultimately, this study will try to find an answer to the following research question: "What factors are the most predictors and influencer on the user's future expectancy and intention to adoption bitcoins?".

It should be noted that 'Bitcoin' usually means the system, while 'bitcoin' or BTC generally means currency unit. However, for ease of understanding, 'bitcoin' will be used for this entire paper. Bitcoin encompasses an electronic, virtual currency with no physical depiction including banknotes or coins [6]. The ecosystem of bitcoin encompasses a network comprising users in communication with each other with the usage of the bitcoin protocol through the internet as shown in Figure 1. This protocol is accessible as an open-source software application, and it enables users to keep and hand over bitcoins to buy and sell goods, or to swap bitcoins for other currencies. Bitcoins are produced within the network during the handling of transactions in a bitcoin mining process.


but machine-to-machine payment using the Bitcoin protocol could allow for direct payment between

Figure 1. How bitcoins work [10] 
The bitcoin network began in 2009 and became the most widespread decentralized currency, that in January 2017, the existence of 16 million circulating bitcoins carrying an approximate value of 16 billion US dollars even though the exchange rate appears to be very large [7]. The resilience of and acceptance towards bitcoin have been mainly factored by the currency's strong code and the support given by the currency garners within the computing community. As reported in the literature [8], their reinforcements to the code's technical transformation have created trust amongst users of bitcoin.

Bitcoin is also dubbed as the virtual network currency or digital coins, enabling transfer of digital money among users. Transferrable coins are those carrying a distinctive chain of digital signatures which will be kept within a digital wallet installed on the computer belonging to a user. Several keys will be produced from the digital wallet, and these keys allows the transfer and receipt of coins. In making a transfer, owner of bitcoin employs private digital key for providing the approval to the additional request from the receiver's key for a stringing of preceding transactions. The coin will then be transferred and materializes in the wallet of receiver with a recorded transactions history together with the latest one [9].

\section{LITERATURE REVIEW AND RESEARCH HYPOTHESES}

Considering the impact of IT on the lives of people in just about all aspects, online payment system and digital money are among two of relevant topics for scrutiny. Accordingly, the present study will scrutinize the topic of IT adoption particularly in the arena of online payment system including bitcoins. In the context of digital currency, the system of bitcoin is a popular platform. However, this form of online payment is still in its infancy and considering the constant change of technology and of the need and expectation of users, more exploration is needed. In this regard, many factors have been found to impact user adoption. However, for the context of the present study, the focus will be on the vital aspects of bitcoin and they are also regarded as the factors that impact user adoption of new technology the most. They are as follows: the effect of effort expectancy, performance expectancy, decentralization, adoption risk, perceived trust, social influence on future expectancy and behavioral intention to use bitcoins.

In Abramova and Böhme [5] study, the authors found transaction processing, security and control, and decentralization as the factors that impacting future application of bitcoin. Transaction processing relates to the transaction linked benefits of utilizing bitcoin to make payments, while security and control relates to the viewpoint regarding the overall security of the bitcoin system. As for decentralization, it theorizes valuable implications of the basic design principle of bitcoin. Meanwhile, perceived risk relates to the belief of user regarding the uncertainty and adverse consequences linked with Bitcoin usage for making payments online and for transfers of money. For perceived risk, it involves 4 first-order constructs obtained from the factor analysis, as follows: Financial losses, legal risk, operational risk, and adoption risk. Specifically, financial losses are linked to likely money losses, while Legal Risk relates to an undistinguishable legal status and an absence of general bitcoin regulation.

Meanwhile, operational risk relates to the possible susceptibilities of the system and the irreversibility of bitcoin transactions, and adoption risk [5]. On the other hand, the effect of the variables (effort expectancy, performance expectancy, Decentralization, adoption risk, perceived trust, social influence) on future expectancy and behavioral intention to use bitcoins will be evaluated in this study. Accordingly, the factors will be deliberated in the following section, followed by the construction of the research hypothesis.

\subsection{Behavioral intention (BI)}

Considering the newness of cryptocurrencies for the public, the risk in the process of decisionmaking of using cryptocurrencies needs to be examined. Appositely, Ajzen (1991) and Davis (1986) described behavioral intention as a key factor that predicts the acceptance decision of user in employing new technology. Understandably, people or businesses might demonstrate reluctance in accepting the phenomenon of cryptocurrency because of its newness, as people generally are unwilling to readily accept something that is unknown to them. Relevantly, the notion of virtual wallet might scare the public, and in the context of bitcoin use, Chuen (2015) stated that if it is too technical, it may fail globally [2]. As such, it is crucial to investigate user intention to use bitcoins. Furthermore, considering user intention being the predictor of adoption of new technology, the factors causing the user intention to use bitcoins become the primary aspect. Such factors are crucial in the scrutiny of the present bitcoins usage situation and the influence of these factors in future bitcoins use intention.

From the theory building standpoint, Abramova and Böhme [5] pioneered the use of a TAM model variant to a different domain, contributing to the emergent IS literature on decentralized currencies. Accordingly, perceived benefit, perceived risk and perceived ease of use were employed to predict the usage behavior [11]. Somehow, the consequence of social influence and perceived trust on the user intent of 
bitcoins use have not been addressed [5]. As such, the present study will offer more comprehensive illustration of the factors impacting the adoption of bitcoins. Hence, factors including perceived trust, adoption risk, decentralization, efforts expectancy, performance expectancy and social influence will be addressed in this study as the predictors of intention to use bitcoins.

\subsection{Future expectancy (FE)}

As proposed by the theory, expectation generates a reference frame that enables a comparative evaluation regarding the performance of certain product [12], [13]. Furthermore, the model of expectancy disconfirmation (Oliver 1980; Oliver 1993) is being extensively utilized and broadened in the examination of consumer behavior and usage intentions in terms of certain information technologies. As reported in Wang and Chang (2014), the model appears to be promising in providing explanation and prediction of customer satisfaction.

It is still unknown if or not bitcoin will survive the mainstream commerce [8]. However, supporters are rooting for bitcoin in showing their commitment towards virtual currency. Among Internet pioneers and legislators, the future of bitcoin is being envisioned and deliberated [14]. Relevantly, it is important that the expectation of user is accomplished in the future. People have great expectation from government and from system itself, and it is possible that they expect bitcoins to be the replacement of the presently used payment method or the bitcoin to be under the governance of banks instead of just one party. For people, they will generate future expectations according to the perceived trust of the existing system, effort expectancy, and performance expectancy, benefit of the present system including decentralization of the present system, adoption risk, and social influence. Hence, considering that expectation could include more potential behavioral determinants, it is arguably able to forecast future behavior than intention on its own [15]. Users will develop future expectation if they believe that the present situation is successful. On the other hand, if the existing system failed, the future expectation will be impaired, and this can lead to future system failure as well.

\subsection{Effort expectancy (EE)}

Effort expectancy (EE) entails the level of ease pertaining to a technology usage [16]. As demonstrated in UTAUT, effort expectancy has positive impact on performance expectancy. Hence, users are confident that the use of Bitcoins is easy and needs minimal effort, their expectation towards obtaining the expected performance will be high, or else, it will be low [17], [18]. Also, AbuShanab et al. found a negative but non-significant path between effort expectancy and the intent of customers to utilize the service [19], [20].

Somehow, in bitcoins use, the measuring criteria of effort expectancy are different; it encompasses ease of transactions and interaction with the system only with users gaining complete control. In reality, the empirical researches mostly found that ease of using online transaction or online banking support higher use intention. As such, it can be deduced that if users find that bitcoins platform has ease to use, the rate of adoption would be greater, increasing future expectation. Hence, the hypotheses below are presented:

H1a: The people whom perceived higher levels of effort expectancy when using bitcoins will perceive higher levels of future expectancy.

$\boldsymbol{H} \mathbf{1 b}$ : The people whom perceived higher levels of effort expectancy when using bitcoins will perceive higher levels of behavioral intention to use bitcoins.

\subsection{Performance expectancy (PE)}

Performance expectancy (PE) relates to the degree to which a person is confident that the usage of a given system will assist his or her improvements in job performance [21]. The positive impact of PE on behavioral intention of consumer to use the service has been documented by many past authors [22], [23]. In the context of bitcoins use, it can be assumed that PE could also impact consumer adoption of bitcoins [24]. Furthermore, to certain degree, the practicality of technology can signify the competencies of a given enterprise to some extent, and these are often found to drive trust building of individuals in the enterprise [25]. Hence, this study expects that bitcoins would be more readily trusted if users believe that bitcoins are of value, and this will increase both expectations and intent of users to use the bitcoins in future.

In the context of mobile apps usage's behavioral intention, PE appears to be the strongest determinant [26]. Hence, if consumers perceive values and innovations from the new technology, their readiness in purchasing and pursuing the use of new technology will be greater. Prior to apps usage, consumers will assess PE of new technology particularly in terms of information exchange and communicative messages. As reported in past studies [27], [28], in the context of technology adoption, PE would considerably impact behavioral intention and use behaviour. Rivera et al. [29] found that for 
consumers, their decisions to use (or not use) mobile apps is determined by the usefulness of mobile apps, that is, whether it can simplify the completion of a task. As such, the hypotheses below will be tested:

H2a: The people whom perceived higher levels of performance expectancy when using bitcoins will perceive higher levels of future expectancy.

$\boldsymbol{H} \mathbf{2 b}$ : The people whom perceived higher levels of performance expectancy when using bitcoins will perceive higher levels of behavioral intention to use bitcoins

\subsection{Perceived trust (PT)}

Bitcoin came into existence in 2008 following the incident of financial crisis causing the trust of public towards financial institutions to diminish. Meanwhile, there have been pressures imposed by governments to private intermediaries such as credit card companies to stop the funds flow to WikiLeaks, discontent towards some processing intermediaries such as PayPal, fees charged for cross-border transactions by financial intermediaries such as Western Union. On the other hand, the anonymity and from governing bodies, bitcoin offers a form of currency that is not bound by censorship. Bitcoin is applicable in cross-border transactions incurring very minimal transactional cost. Lastly, among users of bitcoin, they have established a community and to preserve its value, trust of user is placed in computer code and the cooperative strength of the network [8]. Over the long history of currency usage, people have learned that it is built on trust. Contrariwise, in the context of digital currencies, universal trust still cannot be formed because the use experience is too little. Understandably, people or businesses are not likely be involved into what they are not familiar with.

This study thus views perceived trust as among the vital indicator of perceived future expectancy and behavioral intention towards bitcoins usage [30]. This study expects that when user trusts the bitcoins system, he/she will perceive high or low future expectations. Considering that future expectation can motivate users to use the system more, the following hypothesis is postulated:

H3a: The people whom perceived higher levels of trust when using bitcoins will perceive higher levels of future expectancy.

H3b: The people whom perceived higher levels of trust when using bitcoins will perceive higher levels of behavioral intention to use bitcoins.

\subsection{Perceived adoption risk (AR)}

Adoption Risk echoes the doubt towards bitcoin in regards to its future acceptance by traders [5], [31]. Meanwhile, future acceptance has linkage to behavioral intention. Somehow, future expectation may predict why users would be willing take a risk in new technology usage or in using new payment method such as bitcoins. Such risk originates from the discrepancy between the requirement of user and the actual behavior of the new technology that does not give the expected outcome [32], [33]. Relevantly in their study on the use of electronic mobile banking services, luo et al. [22] found that perceived risk includes psychological risk, social risk, economic risk, functional risk, and so forth. The adoption risk occurs during system pre-usage, and this determines user's usage or non-usage of the new technology.

Users of bitcoins have the same concerns as those of mobile banking such as financial frauds caused by private data tampering, and PIN code loss. In this regard, Roy et al. (2016) mentioned the need to decrease perceived risk in bitcoins, just like it should be for mobile banking. Decreased perceived risk will assist in user reassurance while also reducing their expectation of experiencing a loss caused by mobile banking use [31]. In a relevant study by [22], the authors found that user perception of risk has direct linkage to technology acceptance. As such, for this study, adoption risk will be grounded upon future expectancy of users of bitcoins, and in turn, the adoption risk will impact users' behavioral intention towards bitcoins use. Hence, the following hypotheses will be put to test:

H4a: The people whom perceived higher levels of adoption risk when using bitcoins will perceive higher levels of future expectancy.

$\boldsymbol{H}$ 4b: The people whom perceived higher levels of adoption risk when using bitcoins will perceive higher levels of behavioral intention to use bitcoins.

\subsection{Decentralization}

Decentralization is a key feature of cryptocurrencies, among a few [5], implying the absence of third party that would issue currency. Hence, there is no third party to be trusted [9]. Decentralization makes cryptocurrencies distinct from fiat currency with considerable consequences as highlighted below:

- No governmental backing: Cryptocurrencies are not supported by the government and owing to this, cryptocurrencies are not secured by the European deposit guarantee system which safeguards people from

The adoption of bitcoins technology: The difference between perceived future... (Ibrahim Almarashdeh) 
bank collapses, in a sense that if collapse occurs, the government will reimburse certain amount of funds. Providing no guarantee becomes a disadvantage for bitcoin. Accordingly, Rizzo (2014) reported the collapse of bitcoin exchange Mt. Gox in February 2014 causing the loss of 650.000 BTC or approximately $\$ 300$ Million USD from its clients.

- Governmental influence is completely impossible: Monetary policy cannot therefore be imposed on the network. As such, banks' issuance of credit is impossible, unlike the case with fiat money. However, to perceive this as either an advantage or a disadvantage, will actually depend on the stakeholders. Cryptocurrency enthusiasts favor cryptocurrencies for this reason. Contrariwise, from a regulatory perspective, this might not be desired.

This study employs decentralization as a predictor of behavioral intention and future expectation, and it is expected that the advantage of decentralized system usage will increase user intention, considering that it will lead to the decrease in the number of individuals involved in the transaction processing. It is also expected that people would contemplate the future of bitcoins during decentralized system usage, as they will be anticipating something more in future following the success of the existing stage.

H5a: The people whom perceived higher levels of decentralization when using bitcoins will perceive higher levels of future expectancy.

H5b: The people whom perceived higher levels of decentralization when using bitcoins will perceive higher levels of behavioral intention to use bitcoins.

\subsection{Social influence (SI)}

SI relates to the degree to which certain person feels that significant others are of the view that he or she should employ new technology [34]. In the context of this study, the construct is described as the degree to which users are confident that others such as relatives and friends feel that he/she should employ bitcoins services. Accordingly, there are two types of social influence namely external influence (mass media reports, and expert opinions) and interpersonal influence (peers, word-of-mouth, and superiors). In this study, social influence will be referred as interpersonal influence. In the promotion of bitcoins to public, it is vital to consider social influence. As reported in [14], joined by thousands of members, the bitcoin foundation that promotes bitcoin has approximately $\$ 3$ million in dues and donations in bitcoins. In adopting (or not adopting) bitcoins, individuals will be socially affected, and the effect will be based on past experience or on what the society expects from bitcoins in future. As such, this study will test the hypotheses below:

H6a: The people whom perceived higher levels of social influence when using bitcoins will perceive higher levels of future expectancy.

H6b: The people whom perceived higher levels of social influence when using bitcoins will perceive higher levels of behavioral intention to use bitcoins.

The study research model and hypothesis can be surmised in Figure 2.

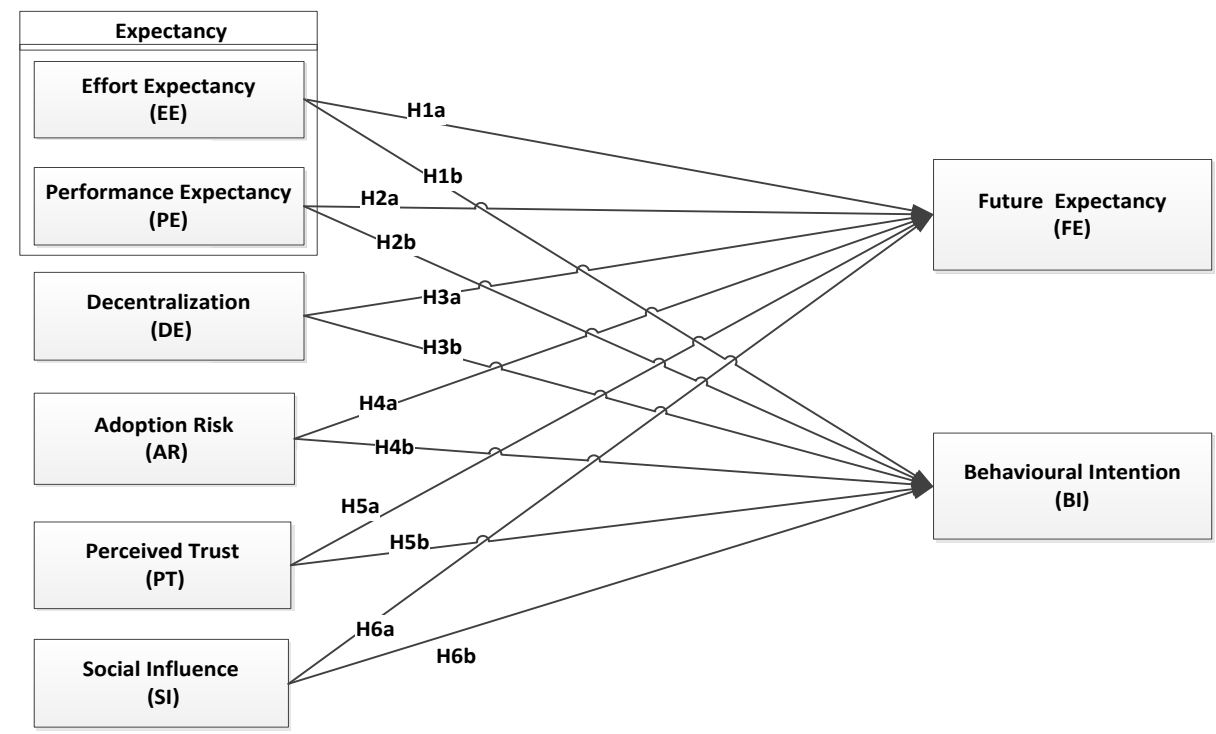

Figure 2. Research model and hypothesis 


\section{METHOD}

An online survey method was chosen in this study, and the target population entails mobile subscribers. Accordingly, an e-mail comprising a cover letter and the linked website addresses was distributed to national panels by an online marketing company. The survey contained six categories of questions as follows: i) perceived trust and adoption risk, ii) decentralization, iii) efforts expectancy and performance expectancy, iv) social influence, v) intention to use bitcoins and future expectancy, and vi) respondents' demographic information

All constructs were gauged using a 5-point Likert scale ranging from $1=$ strongly disagree, to $5=$ strongly agree. In this study, a total of 800 individuals were emailed an invitation to partake the survey, and 293 completed the survey. Hence, the response rate obtained in this study was $23.5 \%$. The obtained data were analyzed in two stages. In the first stage, preliminary analysis was carried out. The purpose was to generate baseline descriptive statistics. During the second stage, a confirmatory analysis was carried out. This was to test the proposed model. Accordingly, AMOS 18 was employed in this study in testing the structural models.

\subsection{Profiles of respondents}

Sample characteristics can be observed in Table 1 . As can be viewed, females comprised $30.4 \%$ of the total sample, while males made up the larger portion at $69.6 \%$. More than half of the respondents $(66.2 \%)$ belonged to the 30-49-year-old category. One distinguished characteristic of the study partakers was that more than half of them $(62.8 \%)$ were highly educated, while the majority of them $(83.3 \%)$ were married.

Table 1. Sample characteristics

\begin{tabular}{llll}
\hline \multirow{4}{*}{ Age } & & $N$ & $\%$ \\
& $25-34$ & 50 & 17.1 \\
\multirow{4}{*}{ Marital status } & $35-49$ & 194 & 66.2 \\
& over 50 & 49 & 16.7 \\
Gender & Single & 49 & 16.7 \\
& Married & 244 & 83.3 \\
Education level & Male & 204 & 69.6 \\
& Female & 89 & 30.4 \\
& Secondary school & 91 & 31.1 \\
& Undergraduate & 12 & 4.1 \\
Total & Postgraduate & 184 & 62.8 \\
& Others & 6 & 2.0 \\
& & 293 & 100 \\
\hline
\end{tabular}

\subsection{Measurement model}

The evaluation of the measurement model was carried out using confirmatory factor analysis (CFA) with the application of a maximum likelihood estimation. This was to test the construct validity, while also testing the underpinning structure of the measures. Accordingly, the measurement statistics for the model variables and the composite reliability of the construct can be observed in Table 2.

There were 28 items altogether, and their reliability is 0.913 , denoting their acceptable consistency. Additionally, as can be observed in Table 2, for all constructs, the Cronbach reliabilities were greater than 0.70, implying tolerable reliability [35]. These obtained outcomes are in agreement with the unidimensionality of the scales. As can be viewed in Table 2, the highest value of reliability is 0.955 , denoting the adoption risk consistency, while decentralization scored the lowest reliability at 0.706 .

All constructs were showing acceptable internal consistency level, as evidenced in the obtained Cronbach's alpha estimates with the range from 89 to 0.93. Since the composite reliabilities were higher than 0.60 , there was sufficient internal consistency of multiple indicators for each construct in the model [36]. The CFA outcomes were demonstrating high factor loadings for all items. In detail, lowest factor loading was on decentralization items namely DE1 (.804), DE2 (.729), and DE3 (.645). Appendix A can be referred for details.

Table 2 also, highlights the test of correlation among constructs. As can be observed, 3 variables show no significant correlation, and these include the correlation between: perceived adoption risk and effort expectancy $(\mathrm{r} .110, \mathrm{P}>.05)$, adoption risk and social influence $(\mathrm{r}-.022, \mathrm{P}>.05)$, and social influence with performance expectancy $(\mathrm{r} .068, \mathrm{P}>.05)$. On the other hand, the rest of the constructs show significant correlation. Here, the larger correlation appears to be between effort expectancy and social influence ( $\mathrm{r} .928$, $\mathrm{P}<.05)$.

Table 3 presents the overall model fit of the proposed model which was statistically evaluated with several goodness-of-fit statistics. Considering the high sensitivity of chi-square statistic towards sample size, 
other extensively employed goodness-of-fit indices were examined as well. As explained in in several researches [36], [37], good fits are affirmed when normed chi-square (CMIN/DF) is lower than 3.

Furthermore, satisfactory fits are achieved when comparative fit index (CFI) and Tucker-Lewis index (TLI) are more than or equivalent to 0.90 , while root mean square error of approximation (RMSEA) is lower than or equivalent to 0.08 [38]. As highlighted in some past studies [36], [37], the following fit indices: CMIN/DF=1.757, $\mathrm{p}<.05$ ( $\leq 3$ recommended); RMR 0.005; GFI=0.997; CFI=0.995; NFI=0.999; and $\mathrm{RMSEA}=0.051$, reliably show a good model fit to the data.

Table 2. Items and constructs characteristics

\begin{tabular}{|c|c|c|c|c|c|c|c|c|c|c|c|}
\hline Code & Construct & $a$ & Mean & $S D$ & $E E$ & $P E$ & $D E$ & $A R$ & $P T$ & $S I$ & $B I$ \\
\hline$E E$ & Effort expectancy & .735 & 2.61 & .402 & 1 & & & & & & \\
\hline$P E$ & $\begin{array}{c}\text { Performance } \\
\text { expectancy }\end{array}$ & .7 .20 & 2.71 & .480 & $.192^{* *}$ & & & & & & \\
\hline$D E$ & Decentralization & .706 & 2.70 & .623 & $.587^{* *}$ & $.273^{* *}$ & & & & & \\
\hline$A R$ & Adoption Risk & .955 & 2.5 & .855 & .110 & $-.298^{* *}$ & $-.191^{* *}$ & & & & \\
\hline$P T$ & Perceived Trust & .875 & 2.42 & .505 & $.765^{* *}$ & $.126^{*}$ & $.837^{* *}$ & $-.135^{*}$ & & & \\
\hline$S I$ & Social Influence & .802 & 2.50 & .418 & $.928^{* *}$ & .068 & $.793^{* *}$ & -.022 & $.825^{* *}$ & & \\
\hline$B I$ & Behavioral Intention & .859 & 2.55 & .524 & $.448^{* *}$ & $.144^{*}$ & $.820^{* *}$ & $-.580^{* *}$ & $.664^{* *}$ & $.644^{* *}$ & \\
\hline$F E$ & Future expectancy & .819 & 2.70 & .707 & $.747^{* *}$ & $.155^{* *}$ & $.834^{* *}$ & $-.460^{* *}$ & $.782^{* *}$ & $.843^{* *}$ & $.887^{* *}$ \\
\hline
\end{tabular}

Table 3. Fit Measures for proposed model

\begin{tabular}{ccc}
\hline Measures & Guidelines & Model Fit \\
\hline CMIN/DF & $\leq 3.0$ & 1.757 \\
P & $\mathrm{p} \geq .05$ & .173 \\
RMR & $\leq .05$ & .005 \\
RMSEA & $\leq .08$ & .051 \\
GFI & $\geq .90$ & .997 \\
NFI & $\geq .90$ & .999 \\
CFI & $\geq .90$ & .995 \\
\hline
\end{tabular}

\section{RESULTS}

\subsection{Hypotheses testing}

Table 4 is concluding the hypothesis testing was achieved with Amos 18. The regression test of the model hypothesis was carried out to measure the user's behavioral intention to use bitcoins and the future expectancy of bitcoins. The obtained results demonstrate support to all the proposed hypotheses as illustrated in the following Table 4.

Table 4. Summary of research hypothesis

\begin{tabular}{|c|c|c|c|c|}
\hline $\mathrm{No}$ & Hypothesis & $B$ & $P$ & Indicator \\
\hline H1a & $\begin{array}{l}\text { The people whom perceived higher levels of effort expectancy when using } \\
\text { bitcoins will perceive higher levels of future expectancy. }\end{array}$ & .251 & $* * *$ & Accepted \\
\hline$H 1 b$ & $\begin{array}{l}\text { The people whom perceived higher levels of effort expectancy when using } \\
\text { bitcoins will perceive higher levels of behavioral intention to use bitcoins. }\end{array}$ & .956 & $* * *$ & Accepted \\
\hline$H 2 a$ & $\begin{array}{l}\text { The people whom perceived higher levels of performance expectancy when using } \\
\text { bitcoins will perceive higher levels of future expectancy. }\end{array}$ & .052 & $* * *$ & Accepted \\
\hline$H 2 b$ & $\begin{array}{l}\text { The people whom perceived higher levels of performance expectancy when using } \\
\text { bitcoins will perceive higher levels of behavioral intention to use bitcoins. }\end{array}$ & .556 & $* * *$ & Accepted \\
\hline$H 3 a$ & $\begin{array}{l}\text { The people whom perceived higher levels of trust when using bitcoins will } \\
\text { perceive higher levels of future expectancy. }\end{array}$ & .466 & $* * *$ & Accepted \\
\hline$H 3 b$ & $\begin{array}{l}\text { The people whom perceived higher levels of trust when using bitcoins will } \\
\text { perceive higher levels of behavioral intention to use bitcoins. }\end{array}$ & .674 & $* * *$ & Accepted \\
\hline$H 4 a$ & $\begin{array}{l}\text { The people whom perceived higher levels of adoption risk when using bitcoins } \\
\text { will perceive higher levels of future expectancy. }\end{array}$ & -.512 & $* * *$ & Accepted \\
\hline$H 4 b$ & $\begin{array}{l}\text { The people whom perceived higher levels of adoption risk when using bitcoins } \\
\text { will perceive higher levels of behavioral intention to use bitcoins. }\end{array}$ & -.940 & $* * *$ & Accepted \\
\hline$H 5 a$ & $\begin{array}{l}\text { The people whom perceived higher levels of decentralization when using bitcoins } \\
\text { will perceive higher levels of future expectancy. }\end{array}$ & .124 & $* * *$ & Accepted \\
\hline$H 5 b$ & $\begin{array}{l}\text { The people whom perceived higher levels of decentralization when using bitcoins } \\
\text { will perceive higher levels of behavioral intention to use bitcoins. }\end{array}$ & .108 & $* * *$ & Accepted \\
\hline H6a & $\begin{array}{l}\text { The people whom perceived higher levels of social influence when using bitcoins } \\
\text { will perceive higher levels of future expectancy. }\end{array}$ & .132 & $* * *$ & Accepted \\
\hline$H 6 b$ & $\begin{array}{l}\text { The people whom perceived higher levels of social influence when using bitcoins } \\
\text { will perceive higher levels of behavioral intention to use bitcoins. }\end{array}$ & -.965 & $* * *$ & Accepted \\
\hline
\end{tabular}




\subsection{Structural equation model}

The structural diagram of the impact of effort expectancy and performance expectancy is illustrated in Figure 3. As can be observed, the estimates of the standardized coefficients are demonstrating the significance of the effect of effort expectancy on perceived future expectation to use bitcoins $(\beta=0.251$; $\mathrm{P}=<.05)$. Furthermore, there appears strong significant path between effort expectancy and behavioral intention to use bitcoins $(\beta=0.965 ; \mathrm{P}=<.01)$.

As can be construed by the standardized coefficients estimates, there was a significant impact of performance expectancy on perceived future expectation $(\beta=0.052 ; \mathrm{P}=<.05)$. Also, there was also strong and significant impact of performance expectancy on behavioral intention to use bitcoins $(\beta=0.556$; $\mathrm{P}=<.01$ ), lending support to Hypotheses $\mathrm{H} 1 \mathrm{a}, \mathrm{H} 1 \mathrm{~b}, \mathrm{H} 2 \mathrm{a}$ and $\mathrm{H} 2 \mathrm{~b}$. It can be concluded that, effort expectancy and performance expectancy show higher impact on the behavioral intention to use bitcoins, greater than perceived future expectancy.



Figure 3. The effect of effort expectancy and performance expectancy

Figure 4 highlights the structural diagram illustrating the impact of adoption risk and perceived trust. As denoted by the standardized coefficients estimates, there is strong and significant impact of perceived trust on future expectancy $(\beta=0.466 ; \mathrm{P}=<.01)$ and, the same strong effect illustrate the path between perceived trust and perceived on behavioral intention to use bitcoins $(\beta=0.674 ; \mathrm{P}=<.01)$.

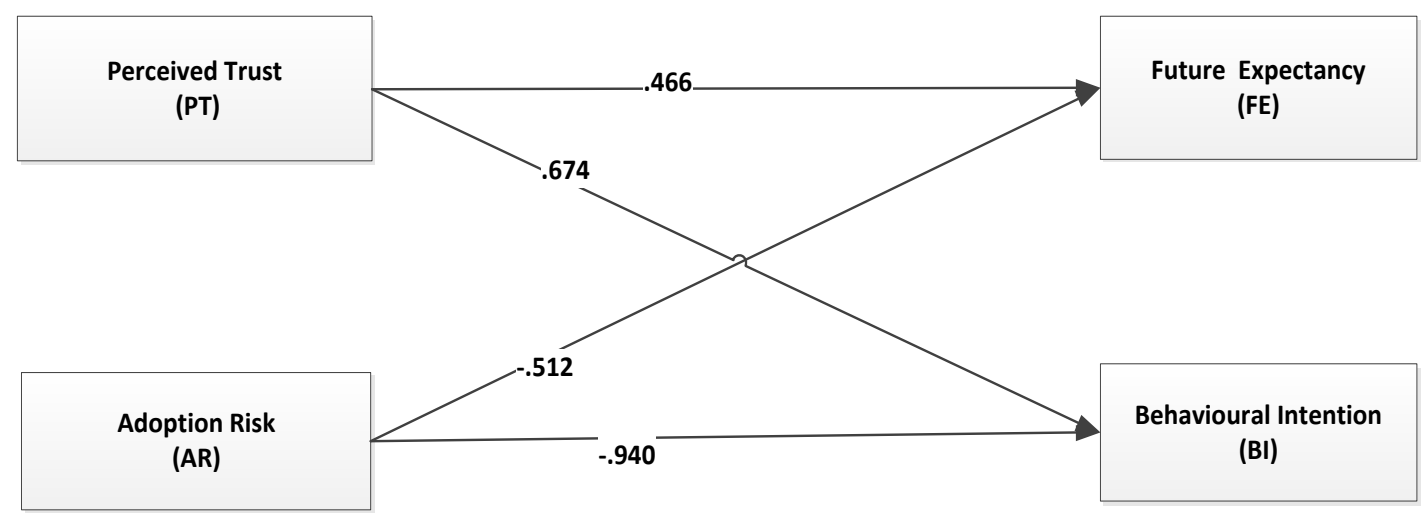

Figure 4. The effect of perceived trust and adoption risk

As evidenced by the standardized coefficients estimates, adoption risk strongly and significantly impacts future expectancy $(\beta=-0.512 ; \mathrm{P}=<.01)$. Meanwhile, adoption risk has adverse strong and significant impact on behavioral intention to use bitcoins $(\beta=-0.940 ; \mathrm{P}=<.01)$, lending support to Hypotheses H3a, H3b, $\mathrm{H} 4 \mathrm{a}$ and $\mathrm{H} 4 \mathrm{~b}$. It can be concluded that the impact of adoption risk and perceived trust is greater on behavioral intention to use bitcoins, more than its effect on perceived future expectancy. 
The following Figure 5 presents the structural diagram that highlights the impact of the benefit of decentralization and social influence (H5a, H6b and H6a, H6b). As denoted by the standardized coefficients estimates, the impact of decentralization benefit on future expectancy appeared to be strongly significant $(\beta=0.124 ; \mathrm{P}=<.01)$, and the same can also be deduced on the path between decentralization benefit on behavioral intention to use bitcoins $(\beta=0.108 ; \mathrm{P}=<.01)$.

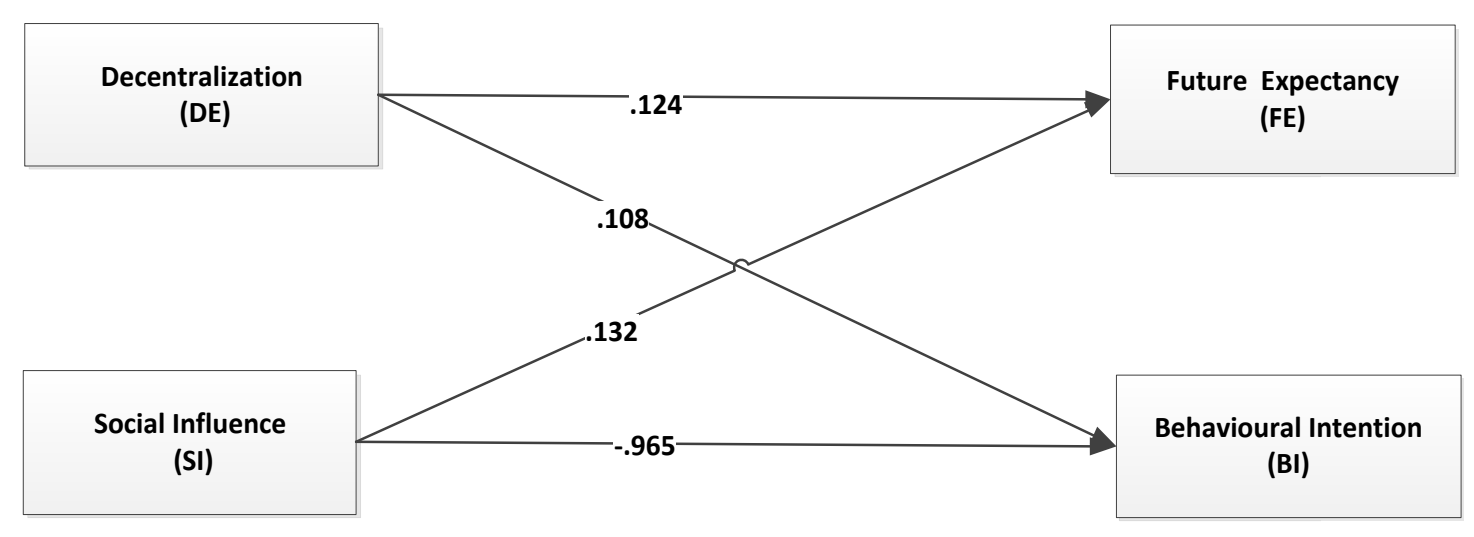

Figure 5. The effect of decentralization and social influence

As a result of the standardized coefficients estimates, the impact of social influence on future expectancy is strong $(\beta=-0.132 ; \mathrm{P}=<.01)$. Additionally, a significant strong negative impact of social influence on behavioral intention to use bitcoins appears to exist as well $(\beta=-0 .-0.965 ; \mathrm{P}=<.01)$, lending support to Hypotheses H5a, H5b, H6a and H6b. It can be concluded that the impact of benefit of decentralization appears to be stronger on future expectancy as opposed to on behavioral intention to use bitcoins. Meanwhile, the effect of social influence on future expectancy is significantly positive, but the impact of social influence on behavioral intention to use bitcoins is significantly negative.

\section{DISCUSSION AND IMPLICATIONS}

\subsection{Discussion of finding}

Developed countries appear to demonstrate their openness towards cryptocurrencies adoption as opposed to their developing counterparts. In particular, bitcoin in developed countries is considered as electronic service, private money, financial service, payment method, money service businesses, decentralized virtual currency, just to name a few. Meanwhile, in several developing countries, bitcoin as well as other cryptocurrencies are deemed illegal. Such is factored by the fact that bitcoin and other cryptocurrencies are not government issued and controlled. Besides, it is possible to see the involvement of bitcoin in suspicious activities (e.g., terrorism financing, human trafficking, illegal payments, and money laundering). Nonetheless, in some countries like Ecuador and China, the implementation of cryptocurrencies is being contemplated.

There are several advantages associated with bitcoin, and these advantages can indeed assist its future development. For users, the safeguarding of their personal data is more guaranteed. Hence, even when a retailer is experiencing a breach of security, the data of customers remain safeguarded. The use of bitcoin incurs much less transaction costs than those of credit card, by one fifth, but understandably, there is no such thing as perfect system. Somehow, the intents of several developed states and large private companies in adopting blockchain for enhancing the systems of financial and administration implies the presence of other prospects to be explored in future.

There is still very restricted amount of empirical studies regarding the perceptions of bitcoin users [5], and with the existing ones, almost all are exploratory and provide just the accumulated descriptive data, such as studies on the description of the bitcoin community [39], country-specific consumer adoption and bitcoin usage [40], or on user experiences regarding security and privacy of bitcoin [41]. Hence, more works should be carried out to determine the impacting factors of bitcoin adoption [5]. From the theory building context, this study denotes a primary effort in using a variant of the TAM model and UTAUT theory, while contributing to the expanding IS works on decentralized currencies. 
The authors initiated this work by attempting to address the questions relating to bitcoins adoption. In such attempt, it is acknowledged that it is yet unknown if or not bitcoin decentralization would increase its adoption, or if decentralization will backfire. Apart from that, it is not known if adoption risk, perceived trust and social influence would increase bitcoins adoption among users or if there will still be fears regarding this fairly unfamiliar technology.

Furthermore, the user's future expectation of bitcoins is unknown too, and this leaves doubt on the anticipated good future of bitcoin. For the purpose, the core concepts of UTAUT and TAM were used in this study. This was to ascertain how user perceives the interaction of performance expectancy, effort expectancy, trust, adoption risk, decentralization and social influence with user's future expectation and behavioral intentions to employ bitcoins. As evidenced by the obtained findings, the proposed model is a sound predictor of user's future expectations and intentions towards bitcoins utilization. Hence, all hypotheses proposed by this study were supported.

The outcomes of data analysis demonstrate the significant effect of all proposed hypothesis on the dependent variables. Here, adoption risk $(\beta-.512 * * *)$ and perceived trust $\left(\beta .466^{* * *}\right)$ were showing the strongest effect on future expectancy. Meanwhile, social influence $\left(\beta-.965^{* * *}\right)$, perceived effort expectancy $\left(\beta .956^{* * *}\right)$, adoption risk $\left(\beta-.940^{* * *}\right)$ and perceived trust $\left(\beta .674^{* * *}\right)$ imparted the strongest impact on behavioral intention to use. On the other hand, perceived performance expectancy showed the weakest impact on future expectancy $\left(\beta .052^{*}\right)$.

The differences in size of effect [42] between each independent variable on both dependent variables, namely Future expectations and Behavioral intention, are displayed in Table 5, and as can be observed, effort expectancy significantly affects future expectancy $(\beta .251)$, with stronger effect shown for behavioral intention $(\beta$.956). Furthermore, both effects significantly differ. Nonetheless, it is possible that consumer would have different viewpoints regarding effort expectancy in employing new technology such as bitcoins platform as different from mobile banking.

As can be construed from the obtained outcomes: if people believe that bitcoins are simple to comprehend and use, their future expectation towards bitcoins will increase, and this also will increase their intention to use bitcoins in future. Relevantly, in the adoption of mobile shopping apps, Yang (2015) indicated effort expectancy as a positive predictor. Furthermore, as technology becomes less complicated, some researchers [27] reported that a person's intention to use the technology is expected to increase. Also, other researchers reported a negative but non-significant path between effort expectancy and customers' intention towards the service usage [19], [20].

In this study, performance expectancy demonstrates significance on future expectancy at the P 0.05 level ( $\beta .052)$, but its impact on behavioral intention to use bitcoins is strong at the P 0.001 level with $\beta .556$. Bitcoins are indeed faster and less costly to use as compare to credit cards [43]. Hence, when bitcoins are viewed as beneficial to use for money transactions and fast transaction processing, users' intention to use bitcoins in future will increase. These outcomes are in support of TAM finding particularly concerning performance expectancy being among the strongest intention predictor in the individual TAM [24], [44].

Considering the infancy of cryptocurrencies in terms of their adoption stage, it is still unclear among users regarding their technical competency as well as the security and dependability of the provided services [45]. In this context, a significant difference was discovered between the significant impact of perceived trust on future expectancy ( $\beta .466)$ and behavioral intention ( $\beta .674)$, implying that when people think that bitcoins have high trustworthiness based on the supported security and integrity, intention to use bitcoins will be greater than future expectation of bitcoins. In this regard, Dumitrescu, (2017) warned that all values of the protocol will be lost if the trust gets ruined [43].

The findings evidence the significant negative impact of adoption risk on future expectancy ( $\beta$-.512) and behavioral intention $(\beta-.940)$, and the difference of effect size between both dependent variables appears to be large as well. In the context of bitcoins, adoption Risk reflects the uncertainty pertaining to its future acceptance among traders [5], [31]. Future acceptance appears to have linkage to behavioral intention. However, it can also be a fitting predictor of why the users would take a risk in employing new technology or new method of payment such as bitcoins. Accordingly, risk is caused by the discrepancy between the requirement of customers and the actual performance of the new technology [32]. Hence, customers with lower perception of risk are likely to have more readiness towards new technology adoption [31].

Decentralization is a main feature of cryptocurrencies [5], and as shown in Table 5, there is no statistical contrast between the impact of decentralization on future expectancy $(\beta .124)$ and behavioral intention to use bitcoins $(\beta$.108). The impact of decentralization on both dependent variables is significant and positive, implying the preference of people to engage in transaction activities with no control of third party like money changers or banks. This finding can be linked to Spenkelink (2014) who questioned if or not decentralized cryptocurrency is good for application [46].

The adoption of bitcoins technology: The difference between perceived future... (Ibrahim Almarashdeh) 
Table 5. The effect on future expectation compared to behavioral intention

\begin{tabular}{ccccc}
\hline $\mathrm{H}_{\mathrm{a}} V S \mathrm{H}_{\mathrm{b}}$ & Dependent & Future Expectancy & Behavioral Intention & Effect Size \\
\hline $\mathrm{H} 1 \mathrm{a} v s \mathrm{H} 1 \mathrm{~b}$ & effort expectancy & 0.251 & 0.956 & Large \\
$\mathrm{H} 2 \mathrm{a} v s \mathrm{H} 2 \mathrm{~b}$ & performance expectancy & 0.052 & 0.556 & Large \\
$\mathrm{H} 3 \mathrm{a} v s \mathrm{H} 3 \mathrm{~b}$ & perceived trust & 0.466 & -0.674 & Large \\
$\mathrm{H} 4 \mathrm{a} v s \mathrm{H} 4 \mathrm{~b}$ & adoption risk & -0.512 & 0.940 & Large \\
$\mathrm{H} 5 \mathrm{a} v s \mathrm{H} 5 \mathrm{~b}$ & decentralization & 0.124 & -0.965 & None \\
$\mathrm{H} 6 \mathrm{a} v s \mathrm{H} 6 \mathrm{~b}$ & social influence & 0.132 & & Large \\
\hline
\end{tabular}

It was reported that people acquire and employ behavioral according to what they perceive within their social groupings. Hence, social influence greatly impacts the decisions to adopt new technology [47], [48]. In this study, a significant difference between the impact of social influence on future expectancy and behavioral intention to use bitcoins was found. In particular, social influence has positive impact on future expectancy $(\beta .132)$, but its impact on behavioral intention appears to be negative $(\beta-.965)$, implying the society's perception of the potential of bitcoins, considering the high-speed evolution of technology in this era.

Somehow, at this point, the society might not see the appropriateness of bitcoin use or even recommend its usage to others. This could be factored by its newness and also, there are still a lot of aspects that are not ascertained as yet. Apart from that, the government role and regulation have been dampening people's willingness to adopt bitcoins. Furthermore, this study finds social influence to impact behavioral intention the most. In other words, the community surrounding a person such as the person's family and friends are the greatest influencer to the person's decision to adopt (or not) bitcoins.

\subsection{Theoretical and practical contributions}

This study examined the impacts of performance expectancy, effort expectancy, perceived trust, adoption risk, decentralization and social influence on future expectancy and behavioral intention to use bitcoins. Hence, it presents to the relevant study domain with support towards UTAUT and TAM application.

This study is a valuable expansion to theories on technology acceptance as it is the first of the kind that tested the impact of adoption risk and perceived trust. Furthermore, a new variable namely future expectancy was introduced. This was to predict a general judgment regarding what is expected by the people from a given technology in the future. Additionally, the results from the comparison of the impact of social influence, adoption risk and perceived trust on behavioral intention to utilize new technology obtained in this study enriches the body of knowledge. Also, this study is the first to test together the direct path for the three variables.

This study contributes in the establishment of bitcoins literature, as this technology is still new and has not been comprehensively scrutinized. Additionally, an in-depth view concerning the aspects most crucial in the prediction the intent of customers towards its use and its future expectations for this developing system was successfully established in this study. Also, hands-on guidelines for providers of bitcoins in their selection of an appropriate marketing strategy which could improve bitcoins adoption among users, while also improving the platform's performance according to their future expectations. This study also has surpassed what has been proposed by also recommending new causal paths between the primary antecedents of behavioral intention and future expectancy.

In practice, this study contributes by presenting evidences regarding the crucial impact of social influence, adoption risk and effort expectancy, as these constructs impact users' behavioral intention to use bitcoins the most. Bitcoins should therefore make available an effective, personal and practical program which shall provide training and education to customers regarding how they can engage in efficient bitcoins usage.

Similarly, for any cryptocurrency, aspects associated with performance and effort expectancy must be the focal point. As an example, the maintenance of the system performance of bitcoins and the reduction of the required effort in completing the transaction could enhance the adoption risk customers. In turn, this will increase these customers' trust towards the use of the system. Also, the technical and legal collaboration between provider of bitcoins and authorities in providing decentralized transactions and well-secured platforms for online services or in constructing electronic laws, could increase the intention of customers in bitcoins use.

Also, having the range of financial services offered by bitcoins expanded and sustaining the stability of their performance in an effective and efficient manner on a $24 / 7$ basis will definitely lend support to the role of perceived trust and social influence, and this will contribute to the increase of user's behavioral intention and future expectancy. It is similarly crucial for bitcoins to identify a fitting channel for communication. This is to give assurance to the customers on the advantages that they would gain when they use Bitcoins. 
From the outcomes, this study concludes the negative impact of social influence on bitcoins adoption. This factor appears highly effective in impacting bitcoins adoption. Accordingly, it is crucial that providers of bitcoins maintain and publicly promote bitcoins. Nonetheless, they are still somewhat bound to the role and regulations imposed by the government. In order to achieve public promotion of bitcoins, the system has to first be legalized globally, based on the trusted roles of states government.

Moreover, the adoption of bitcoins could increase if there is awareness among people regarding its benefit. Not only that, the social community demonstrates trust towards the system while the government handles the customer-business relations. For the providers of bitcoins, the findings of this study are of value in the arena of technology acceptance and promotional activities. Also, with the comprehension of customers' future expectations and behavioral intention level, the effective and fruitful establishment of bitcoins is possible.

\subsection{Future research directions and research limitations}

In comprehending what is expected by people from bitcoins in the future and how far they are ready to adopt bitcoins, this study used only few variables namely perceived performance expectancy, effort expectancy, trust, adoption risk, decentralization and social influence. On the other hand, other variables can also be employed as predictors for instance, transaction processing, and facilitating conditions.

Another limitation of this study is its ignoring of the legal effect and trust in government as predictors of bitcoins adoption. For this reason, it would be of value for future works to look into the legal reasons that hinder people from using bitcoins and then examine how trust in government is viewed by people. Furthermore, only one type of risk was used in this study namely adoption risk, and hence, the future research can consider using different types of risk of bitcoins adoption and make comparison with the impact of perceived trust. Apart from that, factors including age, income and education level have the mediating effect on the factors that impact bitcoins adoption, and arguably this study can positively contribute to the expansion to the knowledge of the domain.

\section{CONCLUSION}

This study was looking into the impact of performance expectancy, effort expectancy, perceived trust, adoption risk, decentralization and social influence on future expectancy and behavioral intention to use bitcoins. Hence, this study lends support the application of UTAUT and TAM. Survey method was employed, and the questionnaires were distributed online. Meanwhile, AMOS 18 was employed in hypotheses testing. Among all the proposed hypothesis, adoption risk and perceived trust imparted the strongest impact on future expectancy. Meanwhile, the constructs of social influence, perceived effort expectancy, adoption risk and perceived trust imparted the strongest impact on behavioral intention to use. Among these hypotheses, the impact of perceived performance expectancy on future expectancy appears to be the weakest. Also, social influence appears to be the strongest predictor of behavioral intention to utilize bitcoins negatively. The obtained outcomes present indications for bitcoins in regard to the significant impact of social influence, adoption risk and effort expectancy on users' behavioral intention to use bitcoins. This study contributes to the knowledge domain by scrutinizing bitcoins as more of an innovative technology for online transactions, and thus far, this has not sufficiently examined. Additionally, factors including age, income and education level could be made mediators to the factors that impact bitcoins adoption. Such future work arguably can soundly contribute to the relevant study domain, while also enriching the present knowledge.

\section{APPENDIX}

A. Data description

\begin{tabular}{|c|c|c|c|c|c|}
\hline Code & Construct and Items & alpha & Mean & $S D$ & Loading \\
\hline$P E$ & Performance expectancy & .7 .2 & 2.7133 & .48050 & \\
\hline$P E 2$ & Bitcoins enable faster transaction processing in my payment & & 3.4915 & .97438 & .943 \\
\hline PE4 & If I use bitcoin, I will increase my income profitability & & 2.2560 & .64586 & .956 \\
\hline$E E$ & Effort expectancy & .735 & 2.6132 & .40236 & \\
\hline EE1 & Using bitcoin as a method of payment is clear and understandable to me & & 2.6724 & .50527 & .999 \\
\hline EE4 & Learning to use bitcoin is easy for me & & 3.1672 & .41712 & .918 \\
\hline$D E$ & Decentralization & .706 & 2.7053 & .62302 & \\
\hline
\end{tabular}

The adoption of bitcoins technology: The difference between perceived future... (Ibrahim Almarashdeh) 


\begin{tabular}{|c|c|c|c|c|c|}
\hline Code & Construct and Items & alpha & Mean & $S D$ & Loading \\
\hline$D E 1$ & I use Bitcoin because it is decentralized. & & 2.8294 & .90936 & .804 \\
\hline$D E 2$ & With Bitcoin I do not have to trust any monetary authority. & & 2.6621 & .75750 & .729 \\
\hline$D E 3$ & I use Bitcoin because I disapprove the conventional financial system & & 2.6246 & .66904 & .645 \\
\hline$A R$ & Adoption risk & .955 & 2.5802 & .85581 & \\
\hline$A R 1$ & I believe there is a lack of adoption in commerce in the long term & & 2.5017 & .78786 & .945 \\
\hline$A R 2$ & I believe there is a lack of interoperability with other services & & 2.6587 & .95421 & .984 \\
\hline$P T$ & Perceived trust & .875 & 2.4206 & .50542 & \\
\hline PT1 & Bitcoin has high integrity & & 2.4949 & .77469 & .982 \\
\hline$P T 2$ & Bitcoin can be trusted completely & & 2.5051 & .53393 & .991 \\
\hline PT3 & The bitcoin platform is perfectly honest and truthful & & 2.3413 & .50974 & .988 \\
\hline PT4 & Bitcoin transaction are more secure than credit card transaction & & 2.3413 & .50974 & .988 \\
\hline$S I$ & Social influence & .802 & 2.5040 & .41802 & \\
\hline$S I 1$ & People who can influence my behavior would think that I should use bitcoin & & 2.3481 & .51182 & .933 \\
\hline SI2 & People who are important to me would think that I should use Bitcoin & & 2.1809 & .42769 & .950 \\
\hline SI3 & People who are important to me would find using Bitcoin beneficial & & 2.3379 & .50866 & .794 \\
\hline$B I$ & Behavioral intention & .859 & 2.5503 & .52488 & \\
\hline$B I 1$ & I want to use bitcoin instead of traditional money & & 2.5085 & .78781 & .999 \\
\hline$B I 2$ & I plan to use bitcoin in the nearest future & & 3.1672 & .70905 & .975 \\
\hline$B I 3$ & I prefer to use bitcoin for payment & & 2.1843 & .43023 & .893 \\
\hline$B I 4$ & $\begin{array}{l}\text { If bitcoin is not available as a payment method at suppliers and external vendors, } \\
\text { I will request it }\end{array}$ & & 2.3413 & .50974 & .988 \\
\hline$F E$ & Future expectancy & .819 & 2.7099 & .70793 & \\
\hline FE1 & I think Bitcoin will become a public payment method in future & & 3.0000 & .83584 & .997 \\
\hline$F E 2$ & I think all payments will be done by bitcoin in the future & & 2.3413 & .50974 & .988 \\
\hline FE3 & I think everybody will use bitcoin in the future & & 2.5017 & .78786 & .998 \\
\hline FE4 & I'm expecting to earn more profit by using Bitcoin & & 2.9829 & .99814 & .969 \\
\hline
\end{tabular}

\section{REFERENCES}

[1] I. Almarashdeh, "The important of service quality and the trust in technology on users perspectives to continues use of mobile services," J. of Theoretical and Applied Information Technology, vol. 96, no. 10, pp. 2954-2972, 2018.

[2] D. L. K. Chuen, "Handbook of digital currency: Bitcoin, innovation, financial instruments, and big data," Academic Press, 2015.

[3] J. R. Hendrickson, T. L. Hogan, and W. J. Luther, "The political economy of bitcoin," Economic Inquiry, vol. 54, no. 2, pp. 925-939, 2016, doi: 10.1111/ecin.12291.

[4] H. Halaburda and M. Sarvary, "Beyond bitcoin: The Economics of Digital Currencies," 1st ed. palgrave macmillan, 2016.

[5] S. Abramova and R. Böhme, "Perceived benefit and risk as multidimensional determinants of bitcoin use: a quantitative exploratory study," in Thirty Seventh International Conference on Information Systems, 2016.

[6] I. Almarashdeh, "An Overview Of Technology Evolution: Investigating The Factors Influencing Non-Bitcoins Users To Adopt Bitcoins As Online Payment Transaction Method," Journal of Theoretical and Applied Information Technology, vol. 96, no. 13, pp. 3984-3993, 2018.

[7] H. Vranken, "Sustainability of bitcoin and blockchains," Current opinion in environmental sustainability, vol. 28, pp. 1-9, 2017.

[8] J. Simser, "Bitcoin and modern alchemy: in code we trust," Journal of Financial Crime, vol. 22, no. 2, pp. 156-169, 2015, doi: 10.1108/JFC-11-2013-0067.

[9] A. M. Antonopoulos, "Mastering Bitcoin: Programming the Open Blockchain," $2^{\text {nd }}$ Edition, O'Reilly Media, Inc., 2017.

[10] T. Wan and H. Max, "Bitcoin: Fact. Fiction. Future," Deloitte insights, 2014.

[11] I. Almarashdeh, "Sharing instructors experience of learning management system: A technology perspective of user satisfaction in distance learning course," Computers in Human Behavior, vol. 63, pp. 249-255, 2016, doi: 10.1016/j.chb.2016.05.013.

[12] G. P. Z. Montesdioca and A. C. G. Maçada, "Measuring user satisfaction with information security practices," Computers and Security, vol. 48, pp. 267-280, 2015, doi: 10.1016/j.cose.2014.10.015.

[13] R. L. Oliver, "A cognitive model of the antecedents and consequences of satisfaction decisions," Journal of Marketing Research, vol. 17, no. 4, pp. 460-469, 1980, doi: 10.1177\%2F002224378001700405.

[14] G. Grant and R. Hogan, "Bitcoin: Risks and Controls," Journal of Corporate Accounting and Finance, vol. 26, no. 5, pp. 29-35, 2015, doi: 10.1002/jcaf.22060.

[15] P. R. Warshaw and F. D. Davis, "Disentangling behavioral intention and behavioral expectation," Journal of experimental social psychology, vol. 21, no. 3, pp. 213-228, 1985, doi: 10.1016/0022-1031(85)90017-4.

[16] V. Venkatesh and X. Zhang, "Unified theory of acceptance and use of technology: U.S. vs. China," Journal of Global Information Technology Management, vol. 13, no. 1, pp. 5-27, 2010, doi: 10.1080/1097198X.2010.10856507.

[17] T. Zhou, Y. Lu, and B. Wang, "Integrating TTF and UTAUT to explain mobile banking user adoption," Computers in human behavior, vol. 26, no. 4, pp. 760-767, 2010, doi: 10.1016/j.chb.2010.01.013. 
[18] C. Martins, T. Oliveira, and A. Popovič, "Understanding the Internet banking adoption: A unified theory of acceptance and use of technology and perceived risk application," International Journal of Information Management, vol. 34, no. 1, pp. 1-13, 2014, doi: 10.1016/j.ijinfomgt.2013.06.002.

[19] E. AbuShanab, J. M. Pearson, and A. J. Setterstrom, "Internet banking and customers' acceptance in Jordan: the unified model's perspective," Communications of the Association for information systems, vol. 26, no. 1, pp. 493-525, 2010.

[20] A. A. Alalwan, Y. K. Dwivedi, N. P. Rana, and A. C. Simintiras, "Jordanian consumers' adoption of telebanking: Influence of perceived usefulness, trust and self-efficacy," International Journal of Bank Marketing, vol. 34, no. 5, pp. 690-709, 2016, doi: 10.1108/IJBM-06-2015-0093.

[21] V. Venkatesh, M. Morris, G. Davis, and F. Davis, "User acceptance of information technology: Toward a unified view," Inform Management, vol. 27, no. 3, pp. 425-478, 2003, doi: 10.2307/30036540.

[22] X. Luo, H. Li, J. Zhang, and J. P. Shim, "Examining multi-dimensional trust and multi-faceted risk in initial acceptance of emerging technologies: An empirical study of mobile banking services," Decision support systems, vol. 49, no. 2, pp. 222-234, 2010, doi: 10.1016/j.dss.2010.02.008.

[23] T. Oliveira, M. Faria, M. A. Thomas, and A. Popovič, "Extending the understanding of mobile banking adoption: When UTAUT meets TTF and ITM," International Journal of Information Management, vol. 34, no. 5, pp. 689-703, 2014, doi: 10.1016/j.ijinfomgt.2014.06.004.

[24] Y. Zhang, X. Chen, X. Liu, and N. Zhu, "Exploring trust transfer between internet enterprises and their affiliated internet-only banks: An adoption study of internet-only banks in China," Chinese Management Studies, vol. 12, no. 1, pp. 56-78, 2018, doi: 10.1108/CMS-06-2017-0148.

[25] W. T. Yao-Hua Tan, "Toward a generic model of trust for electronic commerce," International journal of electronic commerce, vol. 5, no. 2, pp. 61-74, 2000, doi: 10.1080/10864415.2000.11044201.

[26] A. Y.-L. Chong, "Predicting m-commerce adoption determinants: A neural network approach," Expert Systems with Applications, vol. 40, no. 2, pp. 523-530, 2013, doi: 10.1016/j.eswa.2012.07.068.

[27] C.-H. Wong, G. W.-H. Tan, S.-P. Loke, and K.-B. Ooi, "Adoption of mobile social networking sites for learning?," Online Information Review, vol. 39, no. 6, pp. 762-778, 2015, doi: 10.1108/OIR-05-2015-0152.

[28] S. S. Al-Gahtani, G. S. Hubona, and J. Wang, "Information technology (IT) in Saudi Arabia: Culture and the acceptance and use of IT," Information and management, vol. 44, no. 8, pp. 681-691, 2007, doi: 10.1016/j.im.2007.09.002.

[29] M. Rivera, A. Gregory, and L. Cobos, "Mobile application for the timeshare industry: The influence of technology experience, usefulness, and attitude on behavioral intentions," Journal of Hospitality and Tourism Technology, vol. 6 , no. 3, pp. 242-257, 2015.

[30] I. Almarashdeh and M. K. Alsmadi, "How to make them use it? Citizens acceptance of M-government," Applied Computing and Informatics, vol. 13, no. 2, pp. 194-199, 2017, doi: 10.1016/j.aci.2017.04.001.

[31] R. Priya, A. V. Gandhi, and A. Shaikh, "Mobile banking adoption in an emerging economy: An empirical analysis of young Indian consumers," Benchmarking: An International Journal, vol. 25, no. 2, pp. 743-762, 2018, doi: 10.1108/BIJ-01-2016-0009.

[32] N. Koenig-Lewis, A. Palmer, and A. Moll, "Predicting Young Consumers' Take Up of Mobile Banking Services," International Journal of Bank Marketing, vol. 28, no. 5, pp. 410-432, 2010, doi: 10.1108/02652321011064917.

[33] I. Almarashdeh, A. Althunibat, and N. F. Elias, "Developing a Mobile Portal Prototype for E-government Services," Journal of Applied Sciences, vol. 14, no. 8, pp. 791-797, 2014, doi: 10.3923/jas.2014.791.797.

[34] B. Kijsanayotin, S. Pannarunothai, and S. M. Speedie, "Factors influencing health information technology adoption in Thailand's community health centers: Applying the UTAUT model," International Journal of Medical Informatics, vol. 78, no. 6, pp. 404-416, 2009, doi: 10.1016/j.ijmedinf.2008.12.005.

[35] U. Sekaran, "Research Methods for Business: A Skill-Building Approach," $4^{\text {th }}$ Edition, John Wiley \& Sons, Inc, 2003.

[36] R. P. Bagozzi and Y. Yi, "On the evaluation of structural equation models," Academic of Marketing Science, vol. 16, no. 1, pp. 74-94, 1988, doi: 10.1007/BF02723327.

[37] A. Davey and J. Savla, "Statistical power analysis with missing data: A structural equation modeling approach," Taylor \& Francis, 2009.

[38] P. M. Bentler, "Comparative fit indexes in structural models," Psychological bulletin, vol. 107, no. 2, pp. 238-246, 1990, doi: 10.1037/0033-2909.107.2.238.

[39] J. Bohr and M. Bashir, "Who Uses Bitcoin? An Exploration of the Bitcoin Community," in 2014 Twelfth Annual Conference on Privacy, Security and Trust (PST), 2014, pp. 94-101, doi: 10.1109/PST.2014.6890928.

[40] A. Kumpajaya and W. Dhewanto, "The Acceptance of Bitcoin in Indonesia: Extended TAM with IDT," Journal of Business and Management, vol. 4, no. 1, pp. 28-38, 2015.

[41] K. Krombholz, A. Judmayer, M. Gusenbauer, and E. Weippl, "The other side of the coin: User experiences with bitcoin security and privacy," in International Conference on Financial Cryptography and Data Security, 2016, pp. 555-580, doi: 10.1007/978-3-662-54970-4_33.

[42] H. Aguinis, J. C. Beaty, R. J. Boik, and C. A. Pierce, "Effect size and power in assessing moderating effects of categorical variables using multiple regression: a 30-year review," Journal of Applied Psychology, vol. 90, no. 1, pp. 94-107, 2005, doi: 10.1037/0021-9010.90.1.94.

[43] G. C. Dumitrescu, "Bitcoin-A Brief Analysis of the Advantages and Disadvantages," Global Economic Observer, vol. 5 , no. 2 , pp. 63-71, 2017. 
[44] F. Davis, "User acceptance of information technology: system characteristics, user perceptions and behavioral impacts," International journal of man-machine studies, vol. 38, no. 3, pp. 475-487, 1993, doi: 10.1006/imms.1993.1022.

[45] S. Anus, F. A. Qureshi, S. Malik, A. Abbasi, A. Chaudhry, and S. N. Mirza, "Trust and initial acceptance of Mobile Banking in Pakistan," International Journal of Scientific and Engineering Research, vol. 2, no. 8, pp. 337-350, 2011.

[46] H. Spenkelink, "The Adoption Process of Cryptocurrencies-Identifying factors that influence the adoption of cryptocurrencies from a multiple stakeholder perspective," Theses, University of Twente, 2014.

[47] S. Rao and I. Troshani, "A Conceptual Framework and Propositions for the Acceptance of Mobile Services," Journal of Theoretical and Applied Electronic Commerce Research, vol. 2, no. 2, pp. 61-73, 2007, doi: $10.3390 /$ jtaer2020014.

[48] H. Amin, R. Baba, and M. Muhammad, "An analysis of mobile banking acceptance by Malaysian customers," Sunway Academic Journal, vol. 4, no. 1, pp. 1-12, 2007. 